\title{
Changeability of Oral Cavity Environment
}

Anna Surdackaa, MD, PhD

Krystyna Strzykała ${ }^{b}, M D, P h D$

Anna Rydzewskac, MD, PhD

\section{ABSTRACT}

Objectives: In dentistry, the results of in vivo studies on drugs, dental fillings or prostheses are routinely evaluated based on selected oral cavity environment parameters at specific time points. Such evaluation may be confounded by ongoing changes in the oral cavity environment induced by diet, drug use, stress and other factors. The study aimed to confirm oral cavity environment changeability.

Methods: 24 healthy individuals aged 20-30 had their oral cavity environment prepared by having professional hygiene procedures performed and caries lesions filled. Baseline examination and the examination two years afterwards, evaluated clinical and laboratory parameters of oral cavity environment. Caries incidence was determined based on DMFT and DMFS values, oral cavity hygiene on Plaque Index (acc. Silness \& Löe) and Hygiene Index (acc. 0 `Leary), and the gingival status on Gingival Index (acc. Löe \& Silness) and Gingival Bleeding Index (acc. Ainamo \& Bay). Saliva osmolarity, pH and concentrations of $\mathrm{Ca}^{2+}, \mathrm{Pi} \mathrm{Na}^{+}, \mathrm{Cl}^{-}$, total protein, albumins, $\mathrm{F}^{-}$and $\mathrm{Sr}^{2+}$ were determined.

Results: The results confirmed ongoing changeability of the oral cavity environment. After 2 years of the study reduction in oral cavity hygiene parameters $\mathrm{PLI}$ and $\mathrm{HI}(\mathrm{P}<0.1)$, and gingival indices as well as lower saliva concentration of $\mathrm{Ca}^{2+}(\mathrm{P}<.001), \mathrm{Pi}(\mathrm{P}<.06), \mathrm{K}^{+}(\mathrm{P}<.04), \mathrm{Sr}^{2+}(\mathrm{P}<.03), \mathrm{Na}^{+}(\mathrm{P}<.1)$, against the baseline values, were observed. Total protein and albumin saliva concentrations were also significantly lower.

Conclusion: Physiological oral cavity environment is subject to constant, individually different, changes which should be considered when analysing studies that employ oral cavity environment parameters. (Eur J Dent 2007;1:14-17)

Key words: Dental caries; Dental plaque; Saliva inorganic and organic components.

\section{INTRODUCTION}

Advanced biochemical and clinical studies, analysing the specific effects of saliva on the oral cavity pathology have recently confirmed saliva to be one of the most important factors with a role in arresting caries progression and possible role in

\footnotetext{
$\square$ a Department of Conservative

Dentistry \& Periodontology,

b Department of Clinical Analytics,

Laboratory of Environmental Protection,

c Department of Biology and Environmental Protection,

Poznañ University of Medical Sciences, Poznañ, Poland

$\square$ Corresponding author: Anna Surdacka

Department of Conservative Dentistry \& Periodontology,

Poznañ University of Medical Sciences, Bukowska $70 \mathrm{Str}$

60-812 Poznañ - Poland

Tel: 0048618547028

e-mail: annasurddamp.edu.pl
}

reversing the initial injury to the hard dental tissues. Saliva can also be the diagnostic fluid both for periodontal and other diseases. ${ }^{1}$

Human saliva lubricates the oral cavity structures and protects teeth and oral mucosa against potentially injurious factors. Reduced saliva flow rate and comorbid reduction of oral defence systems may induce caries and mucosal inflammation. The volume of saliva in the mouth is not constant and is subject to time dependent and inter-individual changes, ${ }^{2-4}$ with $45 \%$ salivary flow rate fluctuations still considered to be physiological. ${ }^{5}$ Saliva flow rate is a very important factor with a major role in determining the saliva composition..$^{6,7}$

Recent studies have revealed various functions 
mediated by both inorganic and organic components of the saliva that should be accounted for when evaluating the effects of human saliva and dental caries pathogenesis. ${ }^{7-9}$ The phenomenon of saliva components adsorption on the teeth surface has been experimentally proven and early carietic lesions may undergo remineralisation as a result of saliva action. ${ }^{10}$ As saliva is in constant contact with teeth, changes in saliva organic and inorganic components should certainly have a major impact on their condition. The composition and specific biological and physicochemical characteristics of saliva maintain physiological equilibrium between demineralization and remineralisation of the enamel.9,11

The aim of the study was to answer the question if there are changes of the resting mixed saliva composition and selected clinical parameters in the same oral environments over a specified time period.

\section{MATERIALS AND METHODS}

Twenty four healthy volunteers aged 20-30, who remained under constant dental care, took part in the study. The study was approved by the Regional Ethics Committee and each of the participants signed the informed consent. In order to determine changeability of clinical and laboratory parameters of the oral cavity environment the evaluation was performed twice - at study beginning (baseline assessment) and after two years. Oral cavity hygiene was evaluated using Plaque Index (PLI) as proposed by Silness and Lö ${ }^{12}$ and Hygiene Index (HI) as proposed by $0{ }^{~}$ Leary. ${ }^{13}$ The condition of the gingiva was assessed based on the values of Gingival Index (GI) developed by Löe and Silness and Gingival Bleeding Index (GBI) proposed by Ainamo and Bay. ${ }^{14}$ The incidence of caries was assessed using DMFT and DMFS values.

Mixed resting saliva was collected before any meals, early in the morning between 7.00 and 9.00 a.m. to avoid circadian variation in its composition. Subject were seated and asked to lean forward. Saliva was drooled at 30 -s intervals into a plastic tube - salivete kit with a cotton swab and without a stimulator (Sarstedt, Germany) ${ }^{15}$ was used for collecting the saliva for subsequent determining of albumin and total protein level, saliva osmolarity and the concentration of inorganic phosphorus, sodium, potassium, chloride and calcium. The measurements were carried out on the day saliva was collected. The saliva for fluoride and strontium concentration was collected to plastic containers, frozen and stored until the day when the assays were to be carried out. The $\mathrm{pH}$ value of the mixed resting saliva was determined using $\mathrm{pH}$-meter $\mathrm{N} 517 \mathrm{pH}$ meter (Poland) with silver chloride electrode filling solution (Orion Res. Inc., USA). The electrode was calibrated against standard pH buffers ( $\mathrm{pH}$ 4.0, 7.0 and 9.3) (Corning Inc. NY, USA), prior to and after each test as well as during tests as necessary.

Saliva concentration of sodium, potassium, and chloride ions was determined with ionoselective method using Corning 644 analyser. ${ }^{16}$ Inorganic phosphorus and ionised calcium concentrations were determined with spectrophotometric method, using Cobas Mira analyser (Roche). ${ }^{16,17}$ Albumin level was assayed with turbidimetric method, ${ }^{18}$ and modified Exton method was used to assay the total protein level. ${ }^{16}$ Saliva osmolarity was determined with crioscopic method with Knauer microosmometer. Saliva strontium concentration was assayed with atomic absorption spectrophotometry with electrothermic atomisation ET AAS, using Varian Spectr AA 20 Plus spectrophotometer. ${ }^{19}$ The results were submitted for statistical analysis and the differences between the baseline values of the analysed parameters and the values obtained after two years were verified with non-parametric Mann-Whitney test.

\section{RESULTS}

Differences between the baseline values of the analysed parameters and the values obtained after two years of the study could be observed (Tables 1 and 2). Mean DMFT values were not significantly changed, yet DMFS values rose slightly (Table 1). The oral cavity hygiene indices (PLI and HI) decreased $(P<.1)$, and so did mean and median

Table 1. Incidence of caries, oral cavity and gingival hygiene at baseline and after 2 years.

\begin{tabular}{lcccccc}
\hline & \multicolumn{3}{c}{ Baseline values } & \multicolumn{3}{c}{ After two years } \\
\cline { 2 - 7 } & $\bar{x} \pm \mathrm{SD}$ & median & $\min -\max$ & $\bar{x} \pm \mathrm{SD}$ & median & $\min -\mathrm{max}$ \\
\hline DMFT & $9.08 \pm 2.75$ & 10.00 & $3.00-14.00$ & $9.45 \pm 3.11$ & 10.00 & $3.00-15.00$ \\
DMFS & $13.75 \pm 5.84$ & 13,00 & $5.00-19.00$ & $14.94 \pm 5.95$ & 14.00 & $5.00-21.00$ \\
$* \mathrm{PLI}$ & $0.52 \pm 0.27$ & 0,50 & $0.21-1.20$ & $0.41 \pm 0.19$ & 0.42 & $0.13-0.80$ \\
$* \mathrm{HI} \%$ & $42.25 \pm 12.79$ & 40.60 & $22.32-62.5$ & $34.04 \pm 7.04$ & 33.03 & $24.11-45.50$ \\
$\mathrm{GI}$ & $0.53 \pm 0.25$ & 0.50 & $0.17-1.00$ & $0.42 \pm 0.20$ & 0.42 & $0.17-0.80$ \\
$\mathrm{GBI} \%$ & $19.45 \pm 9.02$ & 17.90 & $5.36-35.70$ & $0.42 \pm 0.20$ & 16.96 & $5.30-34.80$ \\
\hline$*: \mathrm{P}<1$ & & & & & &
\end{tabular}


values of the gingival status parameters, i.e. GI and GBI (Table 1).

The comparative analysis of mean values of saliva parameters and saliva constituents at baseline and after two years revealed statistically significant decrease in the concentration of calcium $(P<.01)$, phosphorus $(P<.06)$, potassium $(P<.04)$ and strontium $(P<.03)$, with concurrent rise in sodium concentration $(\mathrm{P}<.1)$.

Chloride level, the level of total protein and albumins, as well as osmolarity and $\mathrm{pH}$, did not significantly change against their baseline values. There were, however, significant inter-individual total protein and albumin level differences both at baseline and after 2 years (Table 2).

\section{DISCUSSION}

The oral cavity environment changeability was evaluated at baseline and after two years based on measurements of selected clinical and saliva parameters in the population of patients under constant dental care who regularly used various dentifrices. We observed an improvement of oral cavity hygiene as confirmed by lower mean values of PLI and HI. This change was important for maintaining the incidence of caries in all experimental environments on almost the same level (there were only two new caries lesions on two surfaces of previously filled teeth).

Saliva $\mathrm{pH}$, another major parameter characterising oral cavity environment, remained stable despite individual variations throughout the study period, and the observed $\mathrm{pH}$ values corresponded to those reported by other authors. ${ }^{20}$ Both at baseline and after 2 years (Table 2) the mean resting saliva $\mathrm{pH}$ values observed in the study were lower compared to the values reported by other authors, ${ }^{12}$ though the $\mathrm{pH}$ range was similar, i.e. 6.51 to 7.10 .
After 2 years the level of total protein in the saliva decreased by $55 \%$ against the baseline and the level of albumins decreased by $23 \%$, though not in all of the study subjects the decrease in total protein level was significant. Similarly to other authors, ${ }^{11,21,22}$ the study revealed significant interindividual differences with regard to these parameters which are indicative of strong changeability of saliva proteins level. Saliva albumins level was characterised by similar changeability and other authors have reported both higher, ${ }^{23}$ and similar ${ }^{24}$ mean values of saliva albumins.

Statistically significant differences could be observed between the levels of ionised calcium, inorganic phosphorus, sodium, potassium and strontium at baseline and after two years. It may, therefore, be said that a new state of equilibrium between the parameters that characterise oral cavity environment has developed.

Change in the concentration of some of the saliva constituents are co-responsible for the dynamics of the processes which contribute to development of new equilibrium between teeth remineralisation and demineralisation. ${ }^{9,22,23}$ Teeth demineralisation which leads to development of caries lesions is related to the processes of calcium, inorganic phosphorus and fluoride ions passage from the enamel to the saliva. Oral cavity environment, particularly saliva and the dental plaque, as well as bacteria, provide conditions which facilitate teeth demineralisation. It therefore is still an open question whether the use of oral hygiene products and appropriate sanitation procedures may change the existing tooth-dental plaque-saliva equilibrium. It seems obvious that demineralisation and remineralisation processes are facilitated by oral cavity environment of correspondingly opposite characteristics, with primary role of $\mathrm{Ca}^{2+}$ and $\mathrm{Pi}^{12}$ and potential role of

Table 2. Analysed saliva parameters and components - values at baseline and after 2 years.

\begin{tabular}{|c|c|c|c|c|c|c|}
\hline \multirow[b]{2}{*}{$N=24$} & \multicolumn{3}{|c|}{ Baseline values } & \multicolumn{3}{|c|}{ After two years } \\
\hline & $\bar{x} \pm \mathrm{SD}$ & median & $\min -\max$ & $\bar{x} \pm \mathrm{SD}$ & median & $\min -\max$ \\
\hline $\mathrm{pH}$ & $6.79 \pm 0.13$ & 6.8 & $6.51-7.00$ & $6.84 \pm 0.12$ & 6.81 & $6.65-7.10$ \\
\hline *** $\mathrm{Ca}^{2+}(\mathrm{mmol} / \mathrm{L})$ & $2.48 \pm 0.63$ & 2.32 & $1.75-3.98$ & $0.99 \pm 0.76$ & 0.82 & $0.51-3.20$ \\
\hline *** $\mathrm{Pi} \quad(\mathrm{mmol} / \mathrm{L})$ & $3.47 \pm 0.94$ & 3.29 & $2.02-5.04$ & $5.04 \pm 1.63$ & 4.33 & $3.10-8.17$ \\
\hline * $\quad \mathrm{Na}^{+}(\mathrm{mmol} / \mathrm{L})$ & $45.25 \pm 17.41$ & 46.5 & $15.00-76.00$ & $36.64 \pm 12.27$ & 32 & $18.00-60.00$ \\
\hline ** $\quad \mathrm{K}^{+} \quad(\mathrm{mmol} / \mathrm{L})$ & $21.83 \pm 2.08$ & 22 & $18.00-25.00$ & $20.25 \pm 2.77$ & 19.2 & $17.50-26.00$ \\
\hline $\mathrm{Cl}^{-}(\mathrm{mmol} / \mathrm{L})$ & $47.67 \pm 15.25$ & 48 & $22.00-74.00$ & $45.18 \pm 14.82$ & 41 & $26.00-80.00$ \\
\hline Osmolarity (mOsm / L) & $128.75 \pm 26.12$ & 125 & $100.00-185.00$ & $115.91 \pm 21.19$ & 110 & $90.00-160.00$ \\
\hline Total proteins (mg / 100 ml) & $58.67 \pm 38.88$ & 38 & $23.00-127.00$ & $32.45 \pm 27.98$ & 28 & $10.00-109.00$ \\
\hline Albumins (mg / 100 ml) & $9.46 \pm 9.00$ & 5.4 & $1.02-29.08$ & $7.31 \pm 7.59$ & 6.15 & $1.32-28.60$ \\
\hline $\mathrm{F}^{-} \quad(\mathrm{mg} / \mathrm{L})$ & $0.11 \pm 0.12$ & 0.1 & $0.04-0.40$ & & & \\
\hline ** $\quad \mathrm{Sr}^{2+}(\mu \mathrm{g} / \mathrm{L})$ & $0.98 \pm 0.29$ & 1 & $0.50-1.50$ & $0.79 \pm 0.27$ & 0.8 & $0.50-1.20$ \\
\hline
\end{tabular}


strontium. ${ }^{25}$ Such a hypothesis is confirmed by the results presented in Table 2 which show calcium level decrease of $40 \%$ after 2 years and inorganic phosphorus level increase of about $45 \%$ against the baseline values. The change in the concentration of those ions may be related to the function of the salivary glands which, as a result of repeated stimulation, could secrete saliva of changed composition. Mean mixed resting saliva concentration of $\mathrm{Ca}^{+2}$ at baseline in young adults equalled $2.48 \pm 0.63$ (Table 2) and was higher compared to the results reported by other authors, yet after its decrease over two years it reached concentrations similar to those observed in other studies. ${ }^{26}$ Mean and individual concentrations of inorganic phosphorus in the saliva, both at baseline and after two years of the study, were either similar to the concentrations reported by other authors ${ }^{22}$ or lower. ${ }^{27}$

Oral cavity characteristics and the degree of saliva osmolarity are dependent on protein concentration, but also on the concentration of ionised sodium, potassium and chloride. Any change in saliva osmolarity will affect the processes of diffusion that occur between the solid and the liquid phases in the oral cavity. In this study saliva sodium and potassium concentration exhibited a downward trend, yet the low concentrations were still within the range of normal, physiological values. ${ }^{28}$ Saliva chloride concentration did not significantly change over the 2-year study period.

Saliva strontium level decreased over 2-year study period by a mean value of $5 \%$ against baseline value $(P<.05)$, and this decrease could have been related to changes in strontium concentration in drinking water and food products, ${ }^{29}$ as well as to changing dietary habits.

\section{CONCLUSIONS}

The results obtained in this study allow to conclude that physiological oral cavity environment is subject to constant, individually different changes which should be accounted for when analyzing the results of studies, over a relatively long time period, that employ oral cavity environment parameters and, in particular, when studying the processes of teeth remineralisation.

\section{REFERENCES}

1. Ozmeric N. Advances in periodontal disease markers. Clinica Chimica Acta 2004;343:1-16.

2. Dawes C. Circadian rhythms in human salivary flow rate and composition. $J$ Physiol 1972;220:529-545.

3. Ship JA, Fox PC, Baum BJ. How much saliva is enough? Normal function defined. J Am Dent Assoc 1991;122:63-69.

4. Sreebny LM. Saliva in health and disease: an appraisal and update. Int Dent $J$ 2000;50:140-161.

5. Ghezzi EM, Lange LA, Ship JA. Determination of variation of stimulated salivary flow rates. J Dent Res 2000;79:18741878.
6. Ferguson DB, Botchway CA. Circadian variations in the flow rate and composition of whole saliva stimulated by mastication. Arch Oral Biol 1980;24:877-881.

7. Tenovuo J. Salivary paramaters of relevance for assessing caries activity in individuals and populations. Community Dent Oral Epidemiol 1997;25:82-86.

8. Borella P, Fantuzzi G, Aggazzotti G. Trace elements in saliva and dental caries in young adults. Sci Total Environ 1994; 153:219-224.

9. Lenander-Lumikari M, Loimaranta V. Saliva and dental caries. Adv Dent Res 2000;14:40-47.

10. Dawes C, Weatherell JA. Kinetics of fluoride in the oral fluid. J Dent Res 1990;69:638-644.

11. Lagerlóf F, Oliverby A. Caries-protective factors in saliva. Adv Dent Res 1994;8:229-238.

12. Silness J, Löe H. Periodontal disease in pregnancy. II. Correlation between oral hygiene and periodontal condition. Acta Odont Scand 1964;22:121-135.

13. O 'Leary TJ, Drake RB, Naylor JE. The plaque control record. J Periodontol 1972;42:38-39.

14. Ainamo J, Bay I. Problems and proposal for recording gingivitis and plaque. Int Dent J 1975;25:229-235.

15. Tadeusiak W, Bobilewicz D. Urea concentration in human parotid saliva in relation to the way of sampling. Diagn Lab 1996;32:331-336.

16. Angielski S. Clinical biochemistry and analytics. Warszawa. PZWL 1985: 451.

17. Tietz NW. Fundamentals of clinical chemistry. Philadelphia: W.B. Sanders, 1984:1208.

18. Johnson AM. A new international reference preparation for proteins in human serum. Arch Pathol Lab Med 1993;117: 29-31.

19. Barto R, Sips AJAM, van der Vijgh WJF, Coen Netelenbos J. Sensitive method for analysis of strontium in human and animal plasma by graphite furnace atomic absorption spectrophotometry. Clin Chem 1995;41:1159-1163.

20. Waszkiel D, Andrzejewicz I, Marczuk-Kolada G. Secretion and buffering capacity of saliva in individuals with enamel erosion. Czas Stomat 1998;8:497-503.

21. Bales CW, Freeland-Graves JH, Askey S, Behmardi F, Pobocik R, Fickel J, Greenlee P. Zinc, magnesium, copper, and protein concentrations in human saliva: age- and sexrelated differences. Am J Clin Nutr 1990;51:462-469.

22. Dawes $C$. The effect of flow rate and duration of stimulation on the concentrations of protein and the main electrolytes in human submandibular saliva. Arch Oral Biol 1874; 19:887-895.

23. Richter J, Pelech L. Albumin in the saliva - a significant indicator of the effect of "outdoor schools". Cent Eur J Public Health 1994;2:55-56.

24. Henskens YMC, van der Velden U, Veerman ECI, Nieuw Amerongen AV. Protein, albumin and cystain concentrations in saliva of healthy subjects and of patients with gingivitis or periodontitis. J Periodont Res 1993;28:43-48.

25. Featherstone JDB, Rodgers BE, Smith MW. Physicochemical requirements for rapid remineralization of early carious lesion. Caries Res 1981;15:221-235.

26. Matsuo S, Lagerlof F. Relationship between total and ionized calcium concentrations in human whole saliva and dental plaque fluid. Arch Oral Biol 1991;36:525-527.

27. Ashley FP, Coward PY, Jalil RA, Wilson RF. Relationship between calcium and inorganic phosphorus concentrations of both resting and stimulated saliva and dental plaque in children and young adults. Arch Oral Biol 1991;36:431-434.

28. Lentner C. Geigy Scientific Tables. Vol 1. Units of measurement, body fluids, composition of the body, nutrition. Basle, Switzerland, Ciba-Geigy Lt.,1981,114.

29. Curzon MEJ. Strontium concentrations in whole human saliva. Arch Oral Biol 1984;29:211-214. 